GU J Sci, Part C,9(2): 272-282 (2021)

Gazi Üniversitesi
Fen Bilimleri Dergisi
PART C: TASARIM VE TEKNOLOJI
http://dergipark.gov.tr/gujsc

\title{
Free Vibration Analysis of a Functionally Graded Micro-Beam with Tapered Cross Section
}

\author{
Duygu İPCI $\dot{I}^{1, *}$ (iD) Bora YILDIRIM ${ }^{2}$ iD \\ ${ }^{1}$ Gazi University, Faculty of Technology, Department of Automotive Engineering, 06560, Yenimahalle/Ankara \\ ${ }^{2}$ Hacettepe University, Faculty of Engineering, Department of Mechanical Engineering, 06640, Çankaya/Ankara
}

\section{Article Info}

Research article

Received:22/03/2021

Revision:09/05/2021

Accepted:09/05/2021

\section{Makale Bilgisi}

Araştırmamakalesi

Başvuru: 22/03/2021

Düzeltme: 09/05/2021

Kabul: 09/05/2021

Keywords

Functionally graded materials,

microbeam,

free vibration analysis,

tapered cross-section

\section{Anahtar Kelimeler}

Fonksiyonel

derecelendirilmis

malzemeler,

mikro kiriş,

serbest titreşim analizi,

konik kesit

\begin{abstract}
In this study, the free vibration analysis of a functionally graded (FG) microbeam with tapered cross-section was carried out theoretically. The beam has material distribution according to the power law throughout the thickness. The governing equation was reduced to an ordinary differential equation for a tapered beam with cross-sectional geometry whose width varies exponentially. Vibrations of a FG tapered microbeam was analyzed analytically in the elastic variation range based on the modified stress couple theory. Motion equations and boundary conditions were derived from the Hamilton principle. Analytical results of natural frequencies were calculated for cantilever exponential FG beams. Solutions for natural frequencies were obtained as the ratio of the beam's characteristic size to the material internal length parameter and according to the FGM distribution function characteristics.
\end{abstract}

\section{Fonksiyonel Derecelendirilmiş Konik Kesitli Bir Mikro Kirişin Serbest Titreșim Analizi}

$\ddot{O} \mathbf{z}$

$\mathrm{Bu}$ çalışmada, konik kesitli fonksiyonel derecelendirilmiş (FD) bir mikro kirişin serbest titreşim analizi teorik olarak gerçekleştirilmiştir. Kiriş, kalınlık boyunca güç yasasına göre malzeme dağılımına sahiptir. Yönetici denklem, genişliği üstel olarak değişen bir enine kesit geometrisine sahip konik kiriş için sıradan bir diferansiyel denkleme indirgenmiştir. Fonksiyonel derecelendirilmiş konik bir mikro kirişin titreşimleri, modifiye edilmiş gerilim çifti teorisine dayalı olarak elastik varyasyon aralığında analitik olarak analiz edilmiştir. Hareket denklemleri ve sınır koşulları Hamilton ilkesinden türetilmiştir. Doğal frekansların analitik sonuçları, konsol üstel FD kiriş için hesaplanmıştır. Doğal frekanslar için çözümler, kirişin karakteristik boyutunun malzeme iç uzunluk parametresine oranı olarak ve FDM dağılım fonksiyonu özelliklerine göre elde edilmiştir.

\section{INTRODUCTION}

Functionally graded material is a type of composite material produced to use the toughness property of metal and high thermal resistance of ceramic. In recent years, FD materials are widely used in micro and nanostructured systems such as thin films of shape memory alloys [1], micro and nano-electromechanical systems (MEMS and NEMS) [2-3] biosensors, actuators [4-5], and atomic force microscopes (AFM) [6]. Devices such as MEMS, NEMS, and AKM are formed from beams. Beams can be of fixed or variable cross-section. Analysis of the material's static and dynamic behavior plays a vital role in structures consisting of beams. To determine the operating range of the systems, it is necessary to determine the natural frequencies of the beams. 
Researchers have conducted many studies on the bending, vibration, and static properties of macro-sized FDM beams in the literature. In these studies, classical continuous media theory was used, and solutions were made by considering the change of material properties throughout the thickness [7-10]. There are fewer studies, as the solutions to problems occurring in axially graded beams are problematic due to the multivariate coefficient main equations [11-12]. Elishakoff et al. carried out a study to obtain the more accurate results of beams' natural frequencies with different end support structures by using the semiinverse approach. The semi-inverse method gives a closed-form solution, and this method yield results similar to some special polynomials for a given bending stiffness and bulk density. The authors reported that this method is not suitable for determining higher-order natural frequencies. Huang and Li [13] aimed to determine an FDM beam's natural frequencies by converting the variable coefficient motion equation into the Fredholm equation. With this method, the authors could only estimate the approximate values of natural frequencies. Murin et al. [14] developed an analytical method for beams with variable material properties. Linear beam theory has been used in the formation of the equations; the effect of the moment of inertia, shear force, and mass distribution is considered. In the study, it was assumed that the beam has a constant cross-sectional area. The results were compared with the finite element results and found to be compatible.

The first work on microstructures, R.D. Mindlin [15], carried out on micro-structures with linear elasticity. Fleck and Hutchinson [16] reformulated the macro-dimensional classical coupled-stress theory for analysis of microstructures. Yang F. et al. [17] developed the modified couple stress (strain gradient) theory using the stress pair theory. Park and Gao [18] developed a new model using the Euler-Bernoulli beam method and the modified stress pair theory. They showed that this new model includes an internal material length scale parameter and that the size effect is significantly useful in solutions. They found that the beam has greater flexural stiffness than the classical beam theory, thanks to the newly developed modeling. The difference between the deflections in these two models increased as the beam thickness decreased. It was observed that as the thickness of the beam increased, similar results were obtained in both methods. This modeling is best suited for micro-beam structures.

Akgöz and Civalek [19] combined the Euler-Bernoulli beam and modified stress couple theory to analyze tapered micro-beams' vibration behavior with the axial material distribution. The micro-beam analysis whose material properties change in the axial direction was carried out for the boundary condition with one fixed end and the other free end. The method developed by Rayleigh-Ritz provided an approximate solution to the free transverse vibration problem. The effects of taper and material properties on the natural frequency of the axially functionally graded micro-beam were explained in detail.

Asghari et al. [20] analyzed the size-dependent static and vibration behaviors of microbeams made of FD material analytically in the elastic region, based on the modified coupled-stress theory. The governing equation of motion and boundary conditions are derived based on Hamilton's principle. They obtained the closed-form solution for natural frequency and static deviation depending on the ratio function of the beam's characteristic size to the internal material parameter and the distribution function of the material properties. These results show that when the ratio of the beam's characteristic size to the internal material length parameter is small, the static deflection and natural frequencies obtained from the Modified Coupled-Stress Theory differ significantly compared to the classical beam theory.

This study, it is aimed to adapt the traditional modeling theories used in the vibration analysis of elastic structured macro dimensional beams to micro dimensional functionally graded beams and to obtain free vibration of the material by analytical methods. The motion equations of microbeam having cross-sectional area along their length have been obtained based on the modified coupled-stress theory and Hamilton's principle. The governing equations of the tapered FGM microbeam are solved analytically by regarding the beam's boundary conditions, the cross-sectional area's geometry, the distribution function, and the direction of the material properties.

\section{MATHEMATICAL MODEL}

Functionally graded materials are produced by combining materials inert in a volumetric ratio. A FGM beam seen in Figure 1 has material distribution along the direction of the beam thickness. 


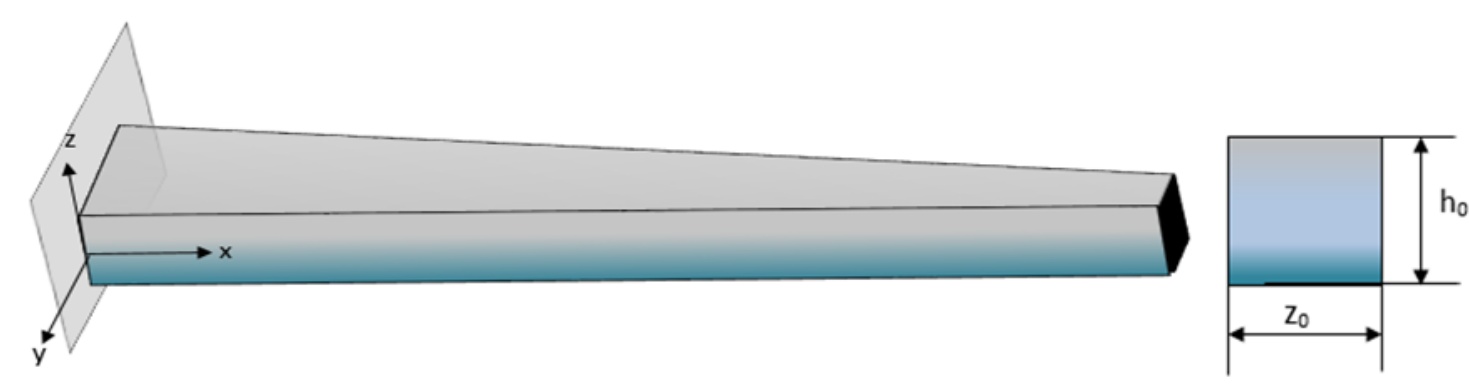

Figure 1. Functional graded beam with material properties varying across thickness (TFGM)

The variations of the beam's material properties according to the $\tilde{z}$ point selected in the thickness direction might be expressed by using power-law distribution functions as follows.

$$
\begin{aligned}
& \rho(\tilde{z})=\rho_{b}+\left(\frac{\tilde{z}}{h}\right)^{n}\left(\rho_{t}-\rho_{b}\right) \\
& E(\tilde{z})=E_{b}+\left(\frac{\tilde{z}}{h}\right)^{n}\left(E_{t}-E_{b}\right) \\
& \mu(\tilde{z})=\mu_{b}+\left(\frac{\tilde{z}}{h}\right)^{n}\left(\mu_{t}-\mu_{b}\right)
\end{aligned}
$$

The equations (1), (2) and (3) are defined the density, elasticity module and shear modulus between the base and the top of the beam, respectively. In the last three equations, $n$ shows the material distribution index. FGM beam forming materials are generally selected as Germanium-Silicon (Ge-Si) elements used in MEMS production [3]. Mechanical properties of Germanium and Silicon materials are given in Table 1.

Table 1. Material properties of Germanium and Silicon

\begin{tabular}{lcc}
\hline & Germanium & Silicon \\
\hline Shear modulus $(\mu)$ & $41 \mathrm{GPa}$ & $79.9 \mathrm{GPa}$ \\
Possion ratio $(v)$ & 0.28 & 0.26 \\
Density $(\rho)$ & $5.33 \mathrm{~g} / \mathrm{cm}^{3}$ & $2.33 \mathrm{~g} / \mathrm{cm}^{3}$ \\
Elasticity modulus $(E)$ & $102.7 \mathrm{GPa}$ & $131 \mathrm{GPa}$ \\
\hline
\end{tabular}

The micro-beam's height, width, length and internal length scale range are $h_{0}=10^{-6} \mathrm{~m}, b=2 h_{0}$, $L=20 h_{0}$ and $0 \leq h / l \leq 10$ respectively. It is assumed that the upper surface of the beam is germanium and the lower surface is silicon.

Yang et al. expressed the modified coupled-stress theory by obtaining the strain energy density in terms of the curvature tensor and the function of the strain tensor. The strain energy (U) occurring in the volume of the beam with linear elastic isotropic material property was written using the modified stress couple theory [21] as follows.

$$
\begin{gathered}
U=\frac{1}{2} \iiint_{v} \sigma_{i j}\left(\varepsilon_{i j}+m_{i j} \chi_{i j}\right) d v \quad(i, j=1,2,3) \\
\sigma_{i j}=\lambda \operatorname{tr}\left(\varepsilon_{i j}\right) I+2 \mu \varepsilon_{i j}
\end{gathered}
$$




$$
\begin{aligned}
& m_{i j}=2 l^{2} \mu \chi_{i j} \\
& \chi_{i j}=\frac{1}{2}\left(\nabla \theta+\nabla \theta^{T}\right) \\
& \varepsilon_{i j}=\frac{1}{2}\left(\nabla u+\nabla u^{T}\right) \\
& \theta_{i j}=\frac{1}{2} \operatorname{curl}(u)_{i} .
\end{aligned}
$$

Using the Euler-Bernoulli based beam theory, the displacement functions given in the last 5 equations might be arranged as

$$
\begin{gathered}
\theta_{y}=-\frac{\partial w(x, t)}{\partial x}, \quad \theta_{x}=\theta_{z}=0 \\
\chi_{x x}=-\frac{1}{2} \frac{d^{2} w}{d x^{2}}, \quad \chi_{y y}=\chi_{z z}=\chi_{x y}=\chi_{x z}=\chi_{y z}=0 \\
\varepsilon_{x x}=-z \frac{d^{2} w}{d x^{2}}, \quad \varepsilon_{y y}=\varepsilon_{z z}=\varepsilon_{x y}=\varepsilon_{x z}=\varepsilon_{y z}=0 \\
\sigma_{x x}=-z E \frac{d^{2} w}{d x^{2}}, \quad \sigma_{y y}=\sigma_{z z}=\sigma_{x y}=\sigma_{x z}=\sigma_{y z}=0 \\
m_{x y}=-l^{2} \mu \frac{d^{2} w}{d x^{2}}, \quad m_{x x}=m_{y y}=m_{z z}=m_{x z}=m_{y z}=0
\end{gathered}
$$

The elasto-dynamic behavior of an anisotropic linear elastic beam is defined by the expanded Hamilton principle. In this principle, the virtual work of the forces acting on the system in a certain time interval and the kinetic and potential energy changes occurring in the system move so that the integral is zero. Based on this approach, by deriving the dynamic equation of motion of the beam with the extended Hamilton principle and disregarding external forces, Equation (4) is arranged as

$$
\frac{\partial^{2}}{\partial x^{2}}\left(\left(E I(x)+l^{2} \mu A(x)\right) \frac{\partial^{2} w(x, t)}{\partial x^{2}}\right)+\rho A(x) \frac{\partial^{2} w(x, t)}{\partial t^{2}}=0
$$

The moment of inertia and cross-sectional area along the length direction of the tapered beam might be defined as

$$
\begin{aligned}
& I(x)=I_{0} i(x) \\
& A(x)=A_{0} a(x) .
\end{aligned}
$$

For the purpose of non-dimensional the beam motion equation, $\eta=\frac{x}{L}, \quad \tau=\frac{t}{t_{0}}, \quad y=\frac{w}{L} \quad$ terms are defined. Eq. 15 is rearranged with last two equations and non-dimensional terms as follow 


$$
\frac{\partial^{2}}{\partial \eta^{2}}\left(\left(E I_{0} i(\eta)+l^{2} \mu A_{0} a(\eta)\right) \frac{\partial^{2} y}{\partial \eta^{2}}\right)+\frac{\rho A_{0} L^{4}}{t_{0}^{2}} a(\eta) \frac{\partial^{2} y}{\partial \tau^{2}}=0
$$

where $i(\eta)$ and $a(\eta)$ denote inertia shape function and area shape function. In the last equation, inertia moment of the beam is defined as $I=I_{0} i(\eta)$ and the components of inertia are expressed as

$$
\begin{aligned}
& I_{0}=c_{i} b_{0} h_{0}{ }^{3} \\
& i(\eta)=y(\eta) z^{3}(\eta) .
\end{aligned}
$$

In Eq. 19 represent cross section width, cross section height and cross-sectional shape function constant respectively. In Eq. $20 y(\eta)$ and $z(\eta)$ denote dimensionless width and height of the beam and are in $0 \leq y(\eta) \leq 1$ and $0 \leq z(\eta) \leq 1$ ranges. The $A=A_{0} a(\eta)$ given in the Eq. 17 cross-sectional area equation was rearranged similar to definition of moment of inertia as follows

$$
\begin{aligned}
& A_{0}=c_{a} b_{0} h_{0} \\
& a(\eta)=y(\eta) z(\eta)
\end{aligned}
$$

where $c_{a}$ presents cross-sectional shape function constant. For the cross section of the beam with varying exponentially, dimensionless width and dimensionless height of the beam might be expressed as

$$
\begin{aligned}
& y(\eta)=e^{\beta_{e}(1-\eta)}, \quad \beta_{e}=\ln \beta \\
& z(\eta)=e^{\alpha_{e}(1-\eta)}, \quad \alpha_{e}=\ln \alpha .
\end{aligned}
$$

For a beam having constant height and exponential variable width, the functions of inertia and cross section might be represented as

$$
\begin{aligned}
& i(\eta)=e^{\beta_{e}(1-\eta)} \\
& a(\eta)=e^{\beta_{e}(1-\eta)}
\end{aligned}
$$

where $\beta_{e}$ denotes taper index of the beam.

Eq. 18 is rearranged by considering the $i(\eta)=a(\eta)$ as follow

$$
\frac{\partial^{2}}{\partial \eta^{2}}\left(i(\eta) \frac{\partial^{2} y}{\partial \eta^{2}}\right)+a(\eta) \frac{\rho A_{0} L^{4}}{\left(E I_{0}+l^{2} \mu A_{0}\right) t_{0}^{2}} \frac{\partial^{2} y}{\partial \tau^{2}}=0 .
$$

The last equation is a function of spatial and time. In order to obtain a solution with time-indepented, last equation is discretized by using the equation of $y(\eta, \tau)=W(\eta) F(\tau)$ as follows

$$
\frac{\partial^{2}}{\partial \eta^{2}}\left(i(\eta) \frac{\partial^{2} W(\eta)}{\partial \eta^{2}} F(\tau)\right)+a(\eta) \frac{\partial^{2} F(\tau)}{\partial \tau^{2}} W(\eta)=0 .
$$


By considering the terms of $\tau=t / t_{0}, \Omega^{4}=\omega^{2} t_{0}^{2}, t_{0}{ }^{2}=\frac{\rho A_{0} L^{4}}{\left(E I_{0}+l^{2} \mu A_{0}\right)}$, time-independent component of the Eq. 28 is expressed as

$$
\frac{\partial^{2}}{\partial \eta^{2}}\left(i(\eta) \frac{\partial^{2} W}{\partial \eta^{2}}\right)-a(\eta) \Omega^{4} W=0
$$

and time-depended component of the Eq. 28 is obtained as

$$
F^{\prime \prime}(\tau)+\omega^{2} F(\tau)=0
$$

The inertia and cross section area functions given in Eqs. 25 and 26 respectively, the motion equation of the tapered beam with exponentially are rearranged with Eq. 29 as follow

$$
\frac{d^{2}}{d \eta^{2}}\left(e^{-\beta_{e} \eta} \frac{d^{2} W}{d \eta^{2}}\right)-\Omega^{4} e^{-\beta_{e} \eta} W=0
$$

Solution of the last equation is obtained as

$$
W(\eta)=e^{\delta \eta}\left[C_{1} \cosh \left(\varepsilon_{1} \eta\right)+C_{2} \sinh \left(\varepsilon_{1} \eta\right)+C_{3} \cos \left(\varepsilon_{2} \eta\right)+C_{4} \sin \left(\varepsilon_{2} \eta\right)\right]
$$

The following equations are used to calculate the natural frequency of the beam.

$$
\begin{aligned}
& \varepsilon_{1}=\sqrt{\Omega^{2}+\delta^{2}} \\
& \varepsilon_{2}=\sqrt{\Omega^{2}-\delta^{2}}, \quad \Omega^{2}>\delta^{2} \quad\left(\delta=\beta_{e} / 2\right)
\end{aligned}
$$

The $\Omega^{2}$ symbol indicates the natural frequency of the beam and is only due to the taper structure of the beam.
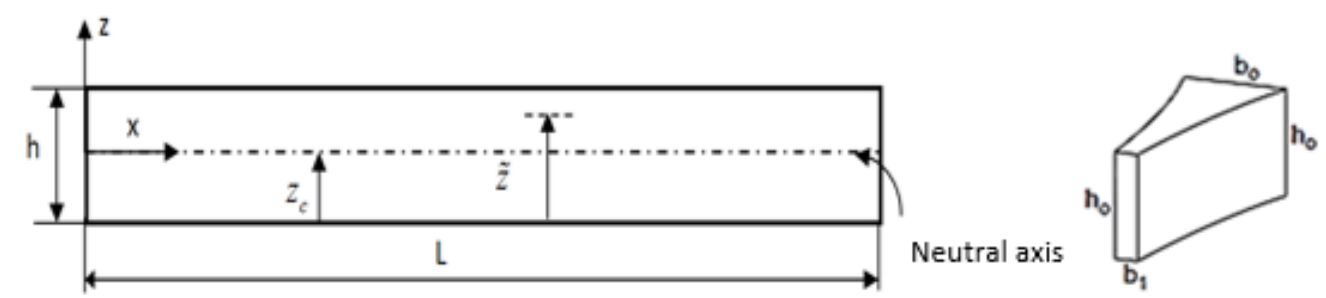

Figure 2. The coordinates and neutral axis of FDM [20]

To calculate the frequency of the FGM beam, the FGM properties of the beam must be defined. During the movement of the beam, there is a neutral axis on the beam that is not subjected to any elongation or shortening. The $z_{c}$ in Figure 2 represents the distance from the bottom of the beam to the neutral axis. To determine the position of the neutral axis, force balance is expressed as

$$
\int_{A} \sigma_{x x} d A=-\int_{A} E(\tilde{z}) z \frac{\partial^{2} w(x, t)}{\partial x^{2}} d A=0
$$

Elastic modulus expression given in the last equation is defined as

$$
\int_{A} E(\tilde{z}) z d A=\int_{A} E(\tilde{z})\left(\tilde{z}-z_{c}\right) d A=0
$$


The distance from the bottom of the beam to the neutral axis is indicated as

$$
z_{c}=\frac{\int_{A} E(\tilde{z}) \tilde{z} d A}{\int_{A} E(\tilde{z}) d A}=\frac{\int_{A} E(\tilde{z}) \tilde{z} b d \tilde{z}}{\int_{A} E(\tilde{z}) b d \tilde{z}}
$$

The Eq. 36 is rearranged with magnitudes of the distance $z_{c}$, power law distribution index $n$ and elastic modulus of the upper $E_{t}$ and lower $E_{b}$ materials of the beam, as follows.

$$
z_{c}=h \frac{\frac{E_{b}}{2}+\frac{\left(E_{t}-E_{b}\right)}{(n+2)}}{E_{b}+\frac{\left(E_{t}-E_{b}\right)}{n+1}}
$$

The moment resultant of the FGM beam is expressed as

$$
M_{x}=\int_{A} E(\tilde{z}) z^{2} \frac{d^{2} w(x, t)}{d x^{2}} d A=\left(E I_{0}\right)_{e q} \frac{d^{2} w(x, t)}{d x^{2}} .
$$

The $\left(E I_{0}\right)_{e q}$ expression in the Eq. 38 is defined as

$$
\left(E I_{0}\right)_{e q}=b\left[h^{3}\left(\frac{E_{b}}{3}+\frac{\left(E_{t}-E_{b}\right)}{n+3}\right)-\tilde{z}_{c} h^{2}\left(E_{b}+\frac{2\left(E_{t}-E_{b}\right)}{n+2}\right)+\tilde{z}_{c}^{2} h\left(E_{b}+\frac{\left(E_{t}-E_{b}\right)}{n+1}\right)\right] .
$$

By substituting equation (37) into above equation, the elastic modulus of the beam for a selected point in the thickness direction is expresed as follows

$$
\begin{gathered}
E(n)=\left(\frac{E_{b}}{3}+\frac{\left(E_{t}-E_{b}\right)}{n+3}\right)-\left(\frac{\frac{E_{b}}{2}+\frac{\left(E_{t}-E_{b}\right)}{(n+2)}}{\left.E_{\mathbf{b}}+\frac{\left(E_{t}-E_{b}\right)}{n+1}\right)\left(E_{b}+\frac{2\left(E_{t}-E_{b}\right)}{n+2}\right)}\right. \\
+\left(\frac{\frac{E_{b}}{2}+\frac{\left(E_{t}-E_{b}\right)}{(n+2)}}{E_{\mathbf{b}}+\frac{\left(E_{t}-E_{b}\right)}{n+1}}\right)^{2}\left(E_{b}+\frac{\left(E_{t}-E_{b}\right)}{n+1}\right)
\end{gathered}
$$

only as a function of the material distribution index. Couple moment of FGM beam is expressed as

$$
Y_{x y}=\int_{A} l^{2} \mu(\tilde{z}) \frac{d^{2} w(x, t)}{d x^{2}} d A=l^{2}\left(\mu A_{0}\right)_{e q} \frac{d^{2} w(x, t)}{d x^{2}} .
$$

The $\left(\mu A_{0}\right)_{e q}$ expression in the Eq. (41) is defined as

$$
\left(\mu A_{0}\right)_{e q}=b h\left[\mu_{b}+\left(\mu_{t}-\mu_{b}\right) \frac{1}{n+1}\right] .
$$


where $\mu_{b}$ and $\mu_{t}$ are shear modulus of the bottom and top surface materials of the beam. The $\left(\rho A_{0}\right)_{e q}$ expression in the Eq. (18) is defined as

$$
\left(\rho A_{0}\right)_{e q}=b h\left[\rho_{b}+\left(\rho_{t}-\rho_{b}\right) \frac{1}{n+1}\right] .
$$

Natural frequency of tapered FGM beam is indicated as

$$
\omega=\Omega^{2} \sqrt{\frac{\left(\left(E I_{0}\right)_{e q}+l^{2}\left(\mu A_{0}\right)_{e q}\right)}{\left(\rho A_{0}\right)_{e q} L^{4}}} .
$$

Two kinds of deformation occur at two different levels during vibration. These are micro rotations at the particle level and macro-deformations at the molecular level. For particle level micro-deformation, the internal length scale determines the micro properties of the particle. It is often referred to as the inner length parameter. The commonly used internal length parameter is one of the main factors in determining the average particle size required to obtain the length scale size. As the average particle size increases / decreases, the size of the length scale will increase/decrease. The inner length scale was defined by Vardoulakis and Sulem [22] as follows

$$
l=\sqrt{\frac{M}{G}}
$$

where $G$ and $M$ denote shear modulus and moment of force respectively. The $\omega_{0}$ symbol presents the frequency for the beam with uniform cross section $\beta=1$ and inside length parameter equal to zero $l=0$ [21]. The frequency of the tapered FGM beam might be calculated with equation given below [20].

$$
\frac{\omega}{\omega_{0}}=\frac{\Omega^{2}}{\Omega_{0}^{2}} \sqrt{1+\frac{\mu_{0}}{E_{0}\left(\frac{h}{l}\right)^{2}}}
$$

\section{NATURAL FREQUENCY OF TFGM BEAM}

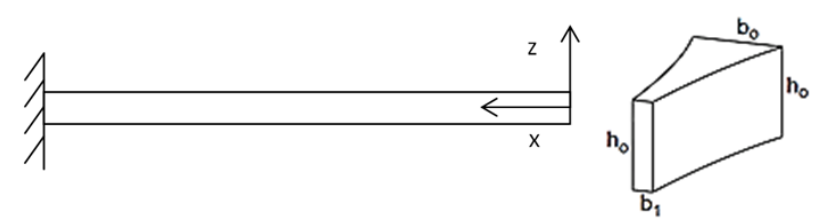

Figure 3. Cantilever FGM beam

Figure 3 indicates the cantilever tapered FGM beam and coordinate position. Boundary conditions for a cantilever beam are expressed as follows.

$$
W(1)=0, \quad W^{\prime}(1)=0, \quad W^{\prime \prime}(0)=0, \quad W^{\prime \prime \prime}(0)=0 .
$$

When the boundary conditions given in the last equation are arranged with Equations (32) and (33), a matrix is obtained as follows. 


$$
\left[\begin{array}{cccc}
\cosh \varepsilon_{1} & \sinh \varepsilon_{1} & \cos \varepsilon_{2} & \sin \varepsilon_{2} \\
\varepsilon_{1} \cosh \varepsilon_{1} & \varepsilon_{1} \sinh \varepsilon_{1} & -\varepsilon_{2} \sin \varepsilon_{2} & \varepsilon_{2} \cos \varepsilon_{2} \\
\delta^{2}+\varepsilon_{1}^{2} & 2 \delta \varepsilon_{1} & \delta^{2}-\varepsilon_{2}^{2} & 2 \delta \varepsilon_{2} \\
\delta^{3}+3 \delta \varepsilon_{1}^{2} & 3 \delta^{2} \varepsilon_{1}+\varepsilon_{1}^{3} & \delta^{3}-3 \delta \varepsilon_{2}^{2} & 3 \delta^{2} \varepsilon_{2}-\varepsilon_{2}{ }^{3}
\end{array}\right]\left\{\begin{array}{l}
C_{1} \\
C_{2} \\
C_{3} \\
C_{4}
\end{array}\right\}=0
$$

From the solution of the last equation, the natural frequency of the beam due to its conical structure is obtained. Considering the material distribution of the FGM beam, the frequency values obtained by Equation (46) are given in Table 2 . While $h_{0} / l$ is equal to 2, the frequency ratio approaches 1 ; that is, it gives similar result to the classical Euler-Bernoulli theory.

Table 2. Frequency ratios

\begin{tabular}{cccccc}
\hline \multirow{2}{*}{ Beta $(\beta)$} & Power law index $(n)$ & \multicolumn{4}{c}{$\omega / \omega_{0}$} \\
\cline { 2 - 5 } & & $h_{0} / l=0.2$ & $h_{0} / l=0.5$ & $h_{0} / l=1$ & $h_{0} / l=2$ \\
\hline \multirow{3}{*}{0.2} & 0.5 & 17.586 & 7.185 & 3.850 & 2.372 \\
& 1 & 19.242 & 7.835 & 4.155 & 2.497 \\
& 2 & 20.057 & 8.156 & 4.307 & 2.560 \\
& 0 & 20.848 & 8.467 & 4.454 & 2.623 \\
0.5 & 0.5 & 13.533 & 5.529 & 2.963 & 1.825 \\
& 1 & 14.807 & 6.029 & 3.197 & 1.921 \\
& 2 & 15.434 & 6.276 & 3.314 & 1.970 \\
0.8 & 0 & 16.043 & 6.515 & 3.428 & 2.018 \\
& 0.5 & 11.762 & 6.515 & 2.575 & 1.586 \\
& 1 & 12.869 & 5.240 & 2.779 & 1.670 \\
& 2 & 13.414 & 5.454 & 2.880 & 1.712 \\
& & 14.548 & 5.663 & 2.979 & 1.754 \\
\hline
\end{tabular}

Figure 4 indicates the variations of frequency ratio by concerning tapered index $\beta$ for $h_{0} / l=0.5$. When the beta is increasing from 0 to 1 , the frequency ratio decreases with the same trend for all power law indices. It is predicted that the frequency ratios values not change for the same taper index values when the value of $\mathrm{n}$ is 2 or more. For tapered index values between 0 and 0.3 , beam should be designed more precisely, as the frequency rates change rapidly.

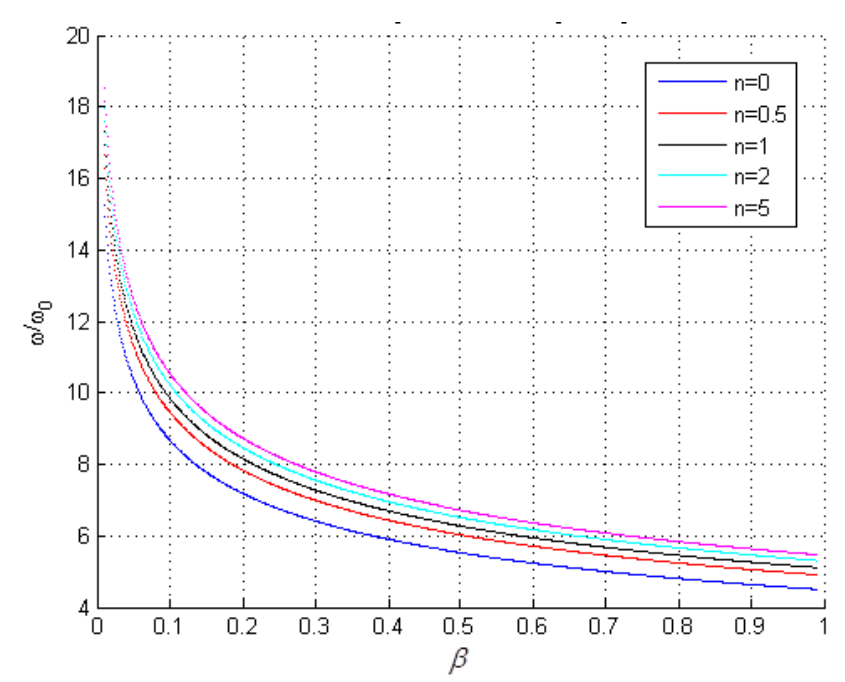

Figure 4. Variations of $\omega / \omega_{0}$ for $h_{0} / l=0.5$ 


\section{CONCLUSIONS}

Except to design parameters of beam taper index and power-law index, the ratio of beam maximum thickness $h_{0}$ to inner length scale $l$ is determined as an additional parameter. With the additional parameter $h_{0} / l$, the shear modulus of the materials is considered for the frequency calculations. The frequency variations of the beam, which depend on the parameter used in the calculations, are presented as the frequency of the tapered beam to the uniform beam. In this study, frequency calculations are carried out for a cantilever TGFM tapered beam made of Germanium and silicon materials. As a result, for all power law indices, effect beam taper index variations on the frequency has the same trend. It is determined that the fastest variation from the frequency of the uniform beam occurs when the taper index is between 0 and 0.3 . While the parameter $h_{0} / l$ is increasing from 0 to 2 , the frequency of the tapered beam approaches to the frequency of uniform beam.

\section{REFERENCES}

[1] Shariat, B. S., Meng, Q., Mahmud, A. S., Wu, Z., Bakhtiari, R., Zhang, J., ... \& Liu, Y. (2017). Functionally graded shape memory alloys: Design, fabrication and experimental evaluation. Materials \& Design, 124, 225-237.

[2] Bogaerts, W., Sattari, H., Edinger, P., Takabayashi, A. Y., Zand, I., Wang, X., ... \& Khan, U. (2020). MORPHIC: Programmable photonic circuits enabled by silicon photonic MEMS. In Silicon Photonics XV (Vol. 11285, p. 1128503). International Society for Optics and Photonics.

[3] Zarezadeh, E., Hosseini, V., \& Hadi, A. (2020). Torsional vibration of functionally graded nano-rod under magnetic field supported by a generalized torsional foundation based on nonlocal elasticity theory. Mechanics Based Design of Structures and Machines, 48(4), 480-495.

[4] Granberry, R., Eschen, K., Holschuh, B., \& Abel, J. (2019). Functionally Graded Knitted Actuators with NiTi-Based Shape Memory Alloys for Topographically Self-Fitting Wearables. Advanced materials technologies, 4(11), 1900548.

[5] Behrouz, S. J., Rahmani, O., \& Hosseini, S. A. (2019). On nonlinear forced vibration of nano cantileverbased biosensor via couple stress theory. Mechanical Systems and Signal Processing, 128, 19-36.

[6] Azari, R., Rezaie, H. R., \& Khavandi, A. (2019). Investigation of functionally graded HA-TiO2 coating on Ti-6Al-4V substrate fabricated by sol-gel method. Ceramics International, 45(14), 17545-17555.

[7] Aydogdu, M., \& Taskin, V. (2007). Free vibration analysis of functionally graded beams with simply supported edges. Materials \& design, 28(5), 1651-1656.

[8] Sankar, B. V. (2001). An elasticity solution for functionally graded beams. Composites Science and Technology, 61(5), 689-696.

[9] Sina, S. A., Navazi, H. M., \& Haddadpour, H. (2009). An analytical method for free vibration analysis of functionally graded beams. Materials \& Design, 30(3), 741-747.

[10] Şimşek, M. (2012). Nonlocal effects in the free longitudinal vibration of axially functionally graded tapered nanorods. Computational Materials Science, 61, 257-265.

[11] Elishakoff, I., \& Candan, S. (2001). Apparently first closed-form solution for vibrating: inhomogeneous beams. International Journal of Solids and Structures, 38(19), 3411-3441.

[12] Elishakoff, I., \& Becquet, R. (2000). Closed-form solutions for natural frequency for inhomogeneous beams with one sliding support and the other pinned. Journal of Sound and Vibration, 238(3), 529539. 
[13] Huang, Y., \& Li, X. F. (2010). A new approach for free vibration of axially functionally graded beams with non-uniform cross-section. Journal of sound and vibration, 329(11), 2291-2303.

[14] Murin, J., Aminbaghai, M., \& Kutiš, V. (2010). Exact solution of the bending vibration problem of FGM beams with variation of material properties. Engineering structures, 32(6), 1631-1640.

[15] Mindlin, R. D. (1963). Microstructure in linear elasticity. Columbia Univ New York Dept of Civil Engineering and Engineering Mechanics.

[16] Fleck, N., \& Hutchinson, J. (1997). Strain gradient plasticity (advances in applied mechanics), Vol. 33.

[17] Yang, F. A. C. M., Chong, A. C. M., Lam, D. C. C., \& Tong, P. (2002). Couple stress based strain gradient theory for elasticity. International journal of solids and structures, 39(10), 2731-2743.

[18] Park, S. K., \& Gao, X. L. (2006). Bernoulli-Euler beam model based on a modified couple stress theory. Journal of Micromechanics and Microengineering, 16(11), 2355.

[19] Akgöz, B., \& Civalek, Ö. (2013). Free vibration analysis of axially functionally graded tapered Bernoulli-Euler microbeams based on the modified couple stress theory. Composite Structures, 98, 314-322.

[20] Asghari, M., Ahmadian, M. T., Kahrobaiyan, M. H., \& Rahaeifard, M. (2010). On the size-dependent behavior of functionally graded micro-beams. Materials \& Design (1980-2015), 31(5), 2324-2329.

[21] Kang, Y. A., \& Li, X. F. (2009). Bending of functionally graded cantilever beam with power-law nonlinearity subjected to an end force. International Journal of Non-Linear Mechanics, 44(6), 696-703.

[22] Sulem, J., Vardoulakis, I., \& Papamichos, E. (1995). Microstructure and scale effect in granular rocks. In Continuum Models for Materials with Microstructure (pp. 201-238). New York: Wiley. 